\title{
PERCEPÇÃO DE ALUNOS DA REDE PÚBLICA DE ENSINO A RESPEITO DAS PRINCIPAIS ZOONOSES URBANAS QUE ACOMETEM A POPULAÇÃO DE JOÃO PESSOA, NORDESTE DO BRASIL
}

\author{
Andréa Amorim LEITE ${ }^{1}$; Marcos Antônio Jerônimo $\operatorname{COSTA}^{2}$; Felipe Eduardo da Silva \\ SOBRAL $^{3}$; Maria Railma Vieira de FREITAS ${ }^{4}$
}

\footnotetext{
${ }^{1}$ Doutoranda em Desenvolvimento e Meio Ambiente (PRODEMA)/Universidade Federal da Paraíba (UFPB), Brasil. E-mail: andreaamorim.bio@gmail.com

${ }^{2}$ Doutor em Ciências Biológicas (Zoologia)/UFPB, Brasil. E-mail: marcoscostajp@gmail.com

${ }^{3}$ Mestre em Sistema Agrossilvipastoril no Semiárido (Zootecnia)/Universidade Federal de Campina Grande (UFCG), Brasil. E-mail: felipe_eduardo_med_vet@hotmail.com

${ }^{4}$ Bióloga/Universidade Estadual da Paraíba (UEPB), Brasil. E-mail: railmabio@gmail.com
}

Primeiramente foi feito um levantamento dos dados epidemiológicos na Secretaria Municipal de Saúde do Município para constatar quais os bairros mais atingidos nos últimos dois anos por doenças enfermidades, em especial, leishmaniose, toxoplasmose, leptospirose e raiva. Posteriormente foi selecionada a escola Estadual de Ensino Infantil e Fundamental Orlando Cavalcanti Gomes, no estado da Paraíba, Nordeste do Brasil, que atendia alunos do $6^{\circ}$ ao $9^{\circ}$ ano. Nesta, os alunos foram questionados a respeito das principais doenças zoonóticas com o objetivo de avaliar o grau de conhecimento sobre a enfermidade e sua profilaxia e tratamento. Com a análise dos dados, verificou-se que o conhecimento destas doenças é quase inexistente embora o convívio com as mesmas seja diário. A partir desta constatação, foi implantado um programa de educação que incluiu palestras, jogos e dinâmicas educativas a respeito das principais zoonoses. Até o momento, há uma boa aceitação e receptividade por parte da escola que já almeja novos projetos em parceria com a Universidade Estadual da Paraíba (UEPB). Quanto aos alunos atendidos, é nítido o interesse e a vontade de participar e fazer visita ao Centro de Vigilância Ambiental e Zoonoses, do município de João Pessoa, para a visualização de animais infectados e a rotina dos funcionários deste órgão.

Palavras-chave: Antropozoonoses; Discentes; Prevenção. 